\title{
Dose Rate Calibration of a Commercial Beta-Particle Irradiator Used in Archeological and Geological Dating
}

October 2004

Prepared by

S. M. Bernal

University of Michigan - Ann Arbor 


\title{
DOCUMENT AVAILABILITY
}

Reports produced after January 1, 1996, are generally available free via the U.S. Department of Energy (DOE) Information Bridge:

Web site: http://www.osti.gov/bridge

Reports produced before January 1, 1996, may be purchased by members of the public from the following source:

\author{
National Technical Information Service \\ 5285 Port Royal Road \\ Springfield, VA 22161 \\ Telephone: 703-605-6000 (1-800-553-6847) \\ TDD: 703-487-4639 \\ Fax: 703-605-6900 \\ E-mail: info@ntis.fedworld.gov \\ Web site: http://www.ntis.gov/support/ordernowabout.htm
}

Reports are available to DOE employees, DOE contractors, Energy Technology Data Exchange (ETDE) representatives, and International Nuclear Information System (INIS) representatives from the following source:

Office of Scientific and Technical Information

P.O. Box 62

Oak Ridge, TN 37831

Telephone: 865-576-8401

Fax: 865-576-5728

E-mail: reports@adonis.osti.gov

Web site: http://www.osti.gov/contact.html

This report was prepared as an account of work sponsored by an agency of the United States Government. Neither the United States government nor any agency thereof, nor any of their employees, makes any warranty, express or implied, or assumes any legal liability or responsibility for the accuracy, completeness, or usefulness of any information, apparatus, product, or process disclosed, or represents that its use would not infringe privately owned rights. Reference herein to any specific commercial product, process, or service by trade name, trademark, manufacturer, or otherwise, does not necessarily constitute or imply its endorsement, recommendation, or favoring by the United States Government or any agency thereof. The views and opinions of authors expressed herein do not necessarily state or reflect those of the United States Government or any agency thereof. 
ORNL/TM-2004/193

DOSE RATE CALIBRATION OF A COMMERCIAL BETA-PARTICLE IRRADIATOR USED IN ARCHEOLOGICAL AND GEOLOGICAL DATING

\author{
S. M. Bernal \\ University of Michigan - Ann Arbor
}

October 2004

\author{
Prepared by \\ OAK RIDGE NATIONAL LABORATORY \\ P.O. Box 2008 \\ Oak Ridge, Tennessee 37831-6285 \\ managed by \\ UT-Battelle, LLC \\ for the \\ U.S. DEPARTMENT OF ENERGY \\ under contract DE-AC05-00OR22725
}





\section{CONTENTS}

Page

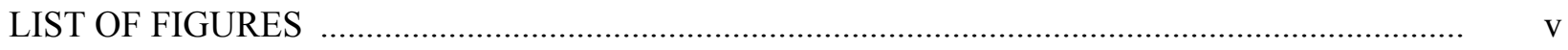

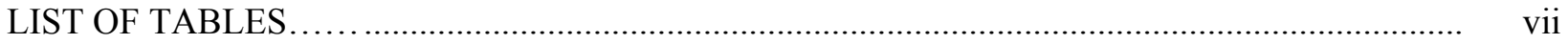

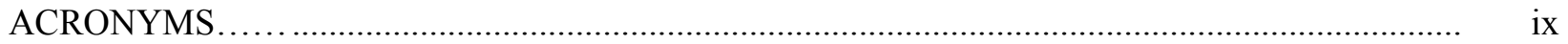

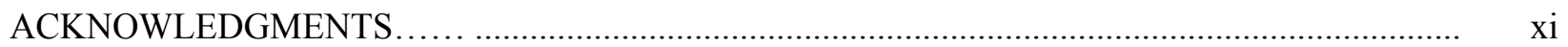

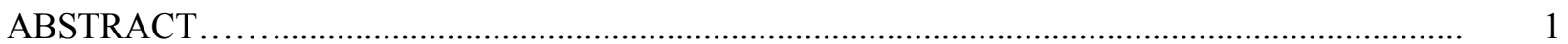

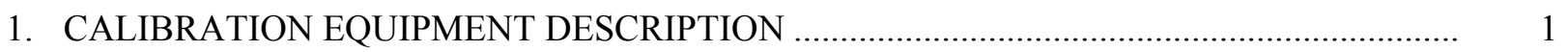

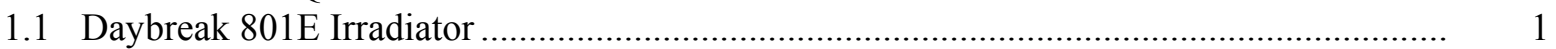

1.2 DOSAR Calibration Laboratory Beta Particle Irradiator ............................................. 1

1.3 Daybreak Model 2200 High-Capacity OSL Reader System................................... 2

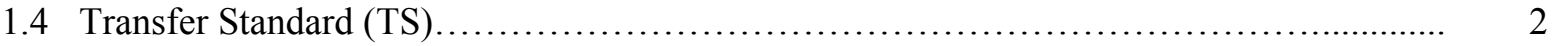

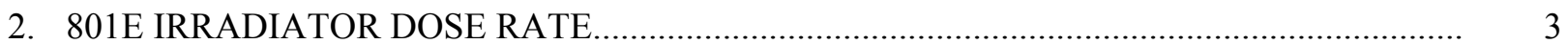

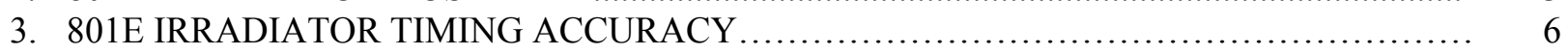

4. SOURCES OF UNCERTAINTY ................................................ 7

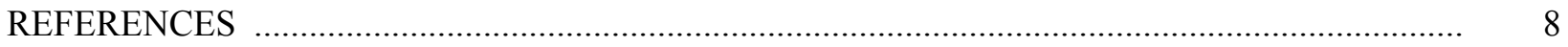

APPENDIX A. DOSAR Calibration Laboratory ${ }^{90} \mathrm{Sr} /{ }^{90} \mathrm{Y}$ Calibration Report..................................... 9 



\section{LIST OF FIGURES}

Figure $\quad$ Page

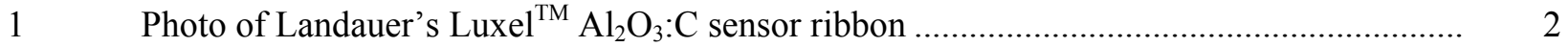

2 Comparison of double-sided tape OSL signal to the Transfer Standard background signal.. 3

3 Response of the TS to a 500-mRad dose and to background dose accumulated during transit

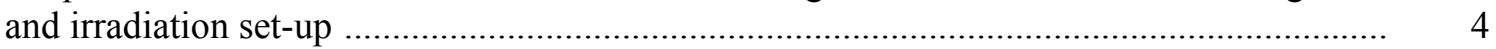

$4 \quad$ Typical OSL curve (or response) for the Transfer Standard ............................................... 4

$5 \quad{ }^{90} \mathrm{Sr} /{ }^{90} \mathrm{Y}$ Dose response curve for the Transfer Standard .................................................. 5

$6 \quad$ Apparent dose rate of the 801E Irradiator as a function irradiation duration........................ 7 



\section{LIST OF TABLES}

Table

Page

$1 \quad$ The transfer standard's (TS) dose response to known beta irradiations $( \pm 5 \%) \ldots \ldots \ldots \ldots \ldots \ldots \ldots \ldots \ldots$

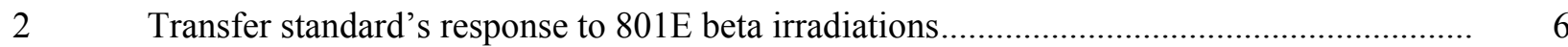





\section{ACRONYMS}

DOSAR Dosimetry Applications Research

LED Light-emitting diode

NBS National Bureau of Standards (now NIST, National Institute of Standards \& Technology)

OSL Optically stimulated luminescence

ORNL Oak Ridge National Laboratory

PMT Photomultiplier tube

TS Transfer standard 



\section{ACKNOWLEDGMENTS}

The author would like to thank James S. Bogard, DOSAR Program leader, Oak Ridge National Laboratory (ORNL), for his thoughtful advice during the course of this work and for use of the Dosimetry Applications Research (DOSAR) Calibration Laboratory. The author would also like to thank Michael E. Murray and Robert L. Coleman, ORNL, for their advice and help, as well as J. Michael Elam, University of Tennessee - Knoxville, for being available to answer questions and for the use of the Daybreak Nuclear Archeological Dating equipment. This research was supported in part by an appointment to the Office of Civilian Radioactive Waste Management Graduate Fellowship program administered by the Oak Ridge Institute for Science and Education through an interagency agreement between the U.S. Department of Energy, with research being conducted at the Oak Ridge National Laboratory. 



\begin{abstract}
The 801E Multiple Sample Irradiator, manufactured by Daybreak Nuclear Systems, is capable of exposing up to 30 samples to beta radiation by placing each sample one by one directly beneath a heavily shielded ceramic Sr-90/Y-90 source and opening a specially designed shutter. Daybreak Nuclear Systems does not provide the ${ }^{90} \mathrm{Sr} /{ }^{90} \mathrm{Y}$ dose rate to the sample because of variations of up to $20 \%$ in the nominal activity of the beta sources (separately manufactured by AEA Technology). Thus it is left to the end user to determine. Here aluminum oxide doped with carbon $\left(\mathrm{Al}_{2} \mathrm{O}_{3}: \mathrm{C}\right)$, in the form of Landauer's Luxel ${ }^{\mathrm{TM}}$, was irradiated to different known doses using a calibrated ${ }^{90} \mathrm{Sr} /{ }^{90} \mathrm{Y}$ beta particle irradiator, and the OSL signal monitored after each irradiation to generate a calibration curve. Comparison of the OSL Signal from the unknown 801E Irradiator dose with the calibration curve enabled the dose and therefore dose rate to be determined. The timing accuracy of the $801 \mathrm{E}$ Irradiator was also evaluated and found to be $+/-0.5$ seconds. The dose rate of the beta source was found to be $0.147+/-0.007 \mathrm{~Gy} / \mathrm{s}$.
\end{abstract}

\title{
1. CALIBRATION EQUIPMENT DESCRIPTION
}

Calibration of the Daybreak $801 \mathrm{E}$ Irradiator ${ }^{90} \mathrm{Sr} /{ }^{90} \mathrm{Y}$ beta source was accomplished by generating a dose response curve for an $\mathrm{Al}_{2} \mathrm{O}_{3}: \mathrm{C}$ transfer standard (TS) using a calibrated beta particle irradiator. Subsequently the Transfer Standard was exposed to a three second exposure in the 801E Beta Irradiator. The unknown dose delivered by the Irradiator was determined by comparison of the transfer standard's response with its dose response curve. Dose rate was subsequently determined by dividing the absorbed dose by the time of irradiation. The transfer standard dosimeter response was measured using Optically Stimulated Luminescence (OSL) technology with the Daybreak 2200 High Capacity OSL Reader.

All the equipment used in the calibration of the commercial 801E beta irradiator, including the irradiator itself, is located at the Oak Ridge National Laboratory (ORNL) Dosimetry Applications Research (DOSAR) facility in Oak Ridge, Tennessee.

\subsection{Daybreak 801E Irradiator}

The 801E Multiple Sample Irradiator, manufactured by Daybreak Nuclear Systems, is an enclosed, tabletop system housing two sources: a plated ${ }^{241} \mathrm{Am}$ alpha source and a Sr-90/Y-90 ceramic beta source (ORNL Radiation Source Inventory number SR-90-525). The beta source has a nominal activity of 100 $\mathrm{mCi}\left(3.7 \times 10^{9} \mathrm{~Bq}\right)$, as reported by AEA Technology on 13 December 2002. The dose rate to a sample from the beta source is unknown at the time of delivery.

\subsection{DOSAR Calibration Laboratory Beta Particle Irradiator}

The DOSAR Calibration Laboratory beta source is an Isotope Products Lab ${ }^{90} \mathrm{Sr} /{ }^{90} \mathrm{Y}$ beta particle irradiator (ORNL Radiation Source Inventory identification number SR-90-3284) which is supported by an aluminum stand. The top of the stand is shaped like the capital letter " $D$ ". The source is positioned in the center of the straight side of the "D". For this work, the phantom positioned directly across from the source on the curved side of the " $\mathrm{D}$ " was used for all irradiations, where the source to phantom distance was $0.35 \mathrm{~cm}$. The beta particle energies at this point had been previously calibrated using an

extrapolation chamber in units of $\mathrm{H}_{\mathrm{p}}(0.07)$ dose rates, such that the dose rate of the encapsulated ${ }^{90} \mathrm{Sr} /{ }^{90} \mathrm{Y}$ beta source at a tissue depth of $7 \mathrm{mg} / \mathrm{cm}^{2}$ was measured to be $158 \mathrm{mrad} / \mathrm{min}$ when calibrated at $0.35 \mathrm{~m}$ by the National Bureau of Standards (NBS) on August 20, 1983. The computer which controls the 
irradiation timing of the DOSAR Calibration Laboratory source bases exposures lengths on this dose rate. For further information on the calibration of the source please see the Calibration Report in the Appendix.

\subsection{Daybreak Model 2200 High-Capacity OSL Reader System}

The 2200 OSL Reader has a 40-cm, 60-sample platter enclosed within an aluminum casing $50 \times 50 \mathrm{~cm}^{2}$ by $10 \mathrm{~cm}$ (plus the photomultiplier barrel height). An OSL light-emitting diode (LED) excitation array, low dark count photomultiplier tube (PMT) and beta irradiator are all mounted on the top cover, which tilts up manually for access to the sample platter. The beta irradiator is aluminum and lead shielded for minimum unintentional exposure to samples within the Reader, as well as minimum dark counts on the associated photomultiplier tube (PMT) ( $\sim 20$ dark counts per second).

This particular OSL Reader uses 480-nm blue LED light to continuously stimulate a sample in which electrons have been promoted to metastable states by exposure to radiation. During stimulation these electrons de-excite from their metastable state and in the process release energy in the form of visible light, which is recorded by the reader's PMT. The PMT directly counts the single pulses generated from the photons interacting with the photocathode. The total output measured by the PMT is directly proportional to radiation dose received.

\subsection{Transfer Standard}

The detector used as a transfer standard between the calibrated beta source and the 801E Irradiator beta source was composed of Luxel ${ }^{\mathrm{TM}}$, a material developed by Landauer* for their personal dosimetry system. Luxel ${ }^{\mathrm{TM}}$ is made of a thin layer of $\mathrm{Al}_{2} \mathrm{O}_{3}: \mathrm{C}$ powder deposited onto a clear polyester film base. The grain size of the $\mathrm{Al}_{2} \mathrm{O}_{3}: \mathrm{C}$ powder is in the range 20-90 $\mu \mathrm{m}$. The powder layer is protected by a thin polyester tape. Figure 1 shows a sample Luxel ${ }^{\mathrm{TM}}$ ribbon.

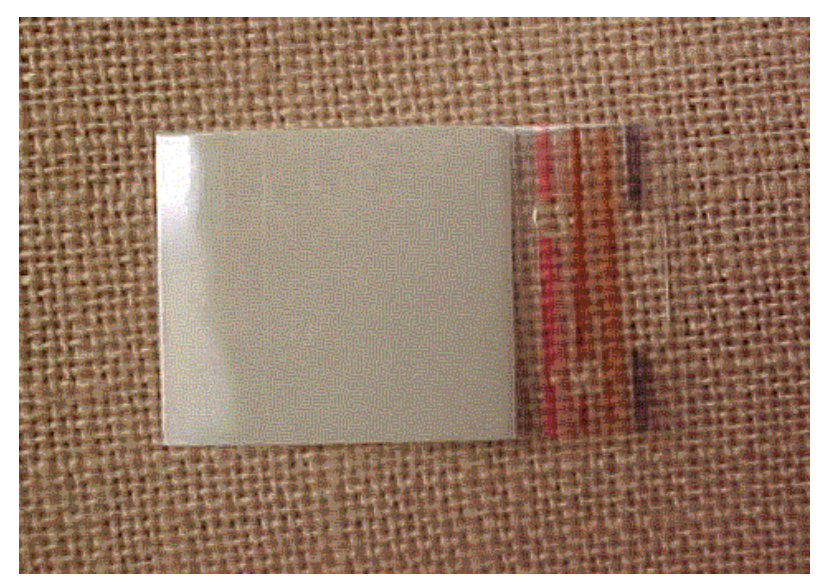

Fig. 1. Photo of $\mathrm{Luxel}^{\mathrm{TM}} \mathrm{Al}_{2} \mathrm{O}_{3}: \mathrm{C}$ sensor ribbon.

The OSL beta dose response for this material has been shown to be linear up to about $10 \mathrm{~Gy}$ (McKeever et al., 1996) and no measurable fading of the OSL signal from $\mathrm{Al}_{2} \mathrm{O}_{3}: \mathrm{C}$ at room temperature has been detected over 100 days (Bøtter-Jensen et al., 1997) In addition, the regenerated OSL signal varies $<1.7 \%$

* Landauer, Inc., Stillwater, Oklahoma 
during multiple irradiations and readouts (Bøtter-Jensen et al., 2003), which is well within the uncertainties of the beta source calibration, and eliminates the need for sensitivity corrections. $\mathrm{Al}_{2} \mathrm{O}_{3}: \mathrm{C}$ also possesses a photon energy response nearly identical to that of quartz and feldspar (Akselrod et al., 1990, 1993).

\section{801E IRRADIATOR DOSE RATE}

The Transfer Standard (TS) was made by cutting one (1) small $0.3 \times 0.6 \mathrm{~cm}$ piece from a ribbon of Luxel $^{\mathrm{TM}}$ material obtained from Landauer Inc. Figure 2.1 shows a sample Luxel ${ }^{\mathrm{TM}}$ ribbon. This size was chosen in order to ensure that this relatively sensitive detector would not emit enough light to damage the PMT on the OSL Reader, no matter how high the dose it received. This piece was then fixed to a 10-mmdiameter aluminum disk (aliquot) using double-sided tape. This step was necessary in order to simulate the normal operating conditions of the 801E Irradiator, in which grains are adhered to aluminum disks before being loaded into the irradiator for exposure to the beta source. Figure 2.2 shows the background OSL signal of the double-sided tape and compares it to that of background for the TS. The extremely low OSL signal of the tape indicates that it could be used without fear of generating interfering signal.

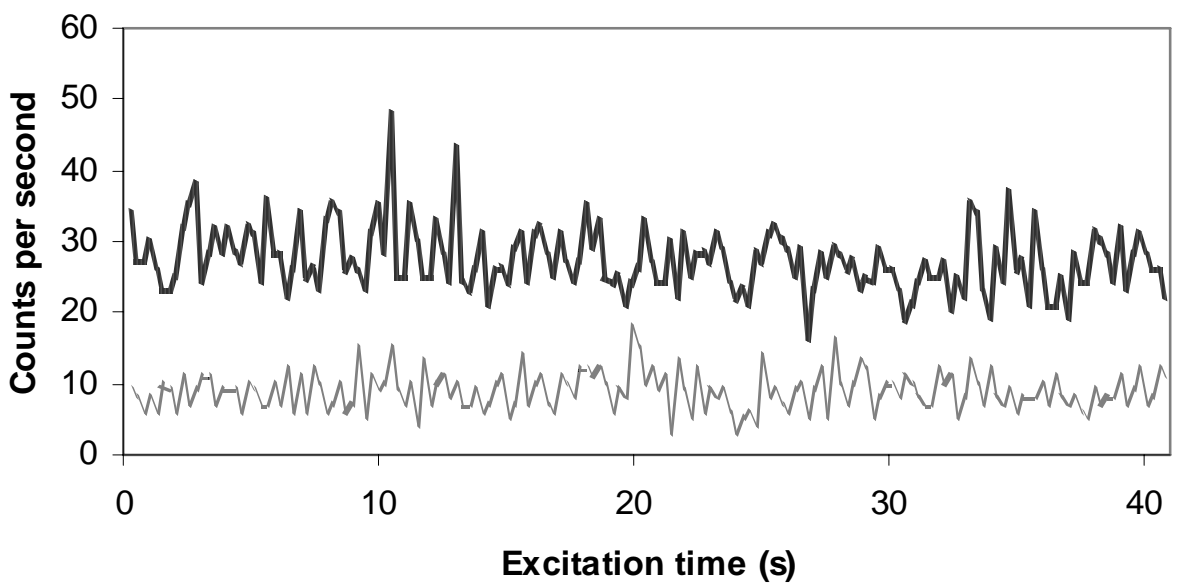

Transfer Standard background signal ___ Double-sided tape signal

\section{Fig. 2. Comparison of double-sided tape OSL signal to the Transfer Standard background signal.}

Before performing irradiations with the calibrated ${ }^{90} \mathrm{Sr} /{ }^{90} \mathrm{Y}$ beta particle irradiator a $1 \mathrm{~cm}$ thick steel block approximately $64 \mathrm{~cm}^{2}$ was taped to the center of the phantom. The addition of the block meant that the source to TS distance would be 0.34 meters. This steel block was included to simulate the $801 \mathrm{E}$ Irradiator environment in which a steel platter, approximately $1 \mathrm{~cm}$ in thickness, cradles the aliquots during all beta exposures.

In order to determine the unknown dose being delivered to a sample, or aliquot, by the $801 \mathrm{E}$ beta source a calibration curve was first generated for the $\mathrm{Al}_{2} \mathrm{O}_{3}: \mathrm{C}$ Transfer Standard. Irradiations were done using the DOSAR Calibration Laboratory's beta particle irradiator to deliver $\mathrm{H}_{\mathrm{p}}(0.07)$ equivalent doses of 300 $\mathrm{mRad}, 400 \mathrm{mRad}, 600 \mathrm{mRad}, 800 \mathrm{mRad}$ and $1000 \mathrm{mRad}$ to the TS. Before each irradiation, all stored OSL signal was cleared by bleaching with $100 \%$ of blue LED power $\left(60 \mathrm{~mW} / \mathrm{cm}^{2}\right)$ until background signal levels were reached. For all exposures the TS was placed in a small plastic baggie which was then taped to the steel block in front of the phantom. Because $\mathrm{Al}_{2} \mathrm{O}_{3}: \mathrm{C}$ is light sensitive (i.e. will lose stored signal if exposed to UV) all irradiations were done in the dark and the TS placed in a light-tight black film container for transfers between the OSL reader and the irradiator. Mounting the TS on the phantom was done as quickly as possible in dim light conditions. To measure background accumulated on the 
sample during travel and set-up, an irradiation was run without turning the source "on" and the TS response measured.

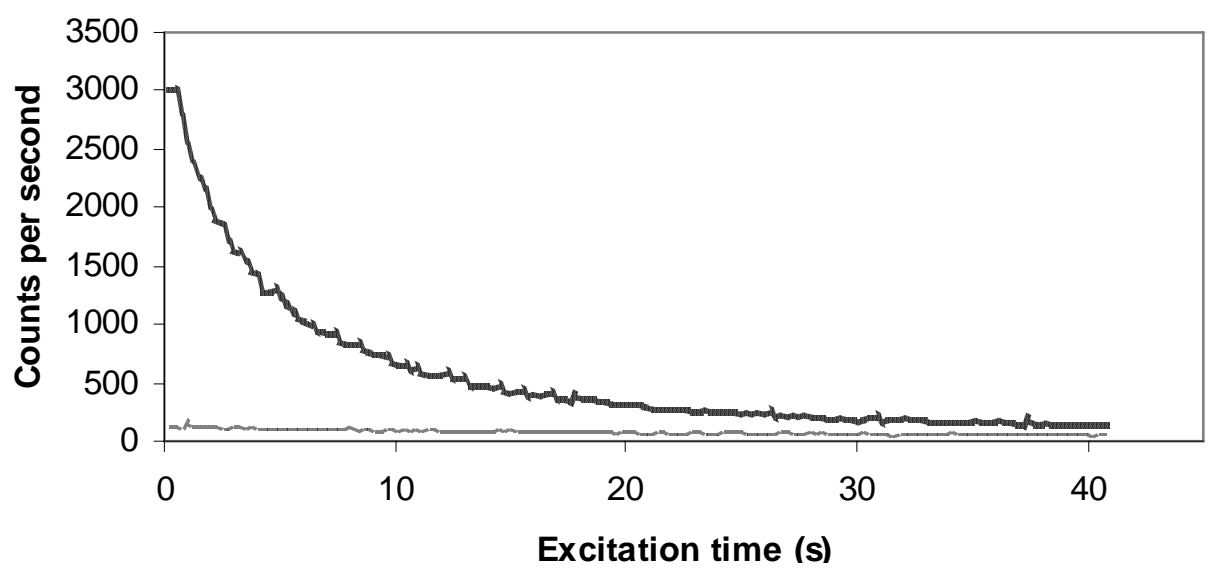

Fig. 3. Response of the TS to a $500 \mathrm{mRad}$ dose and to background dose accumulated during transit and irradiation set-up. Both the 500 -mrad and the transit dose were read at $100 \%$ blue LED power $\left(60 \mathrm{~mW} / \mathrm{cm}^{2}\right)$ for 41 seconds immediately after exposure.

After each irradiation, the TS was immediately placed in the 2200 OSL Reader under red-light conditions for readout. Readout was performed by shining the blue LED on the TS for 51 seconds at $80 \%$ of full power resulting in $48 \mathrm{~mW} / \mathrm{cm}^{2}$ power delivered. After the 51 second stimulation, $100 \%$ blue LED power was used to return the OSL signal of the TS back to background levels. The light emitted from the irradiated sample was then recorded by the PMT generating an "OSL curve" plot, or counts per second as a function of excitation time, which was stored on the control computer for the system. See Figure 2.4 below for an example curve.

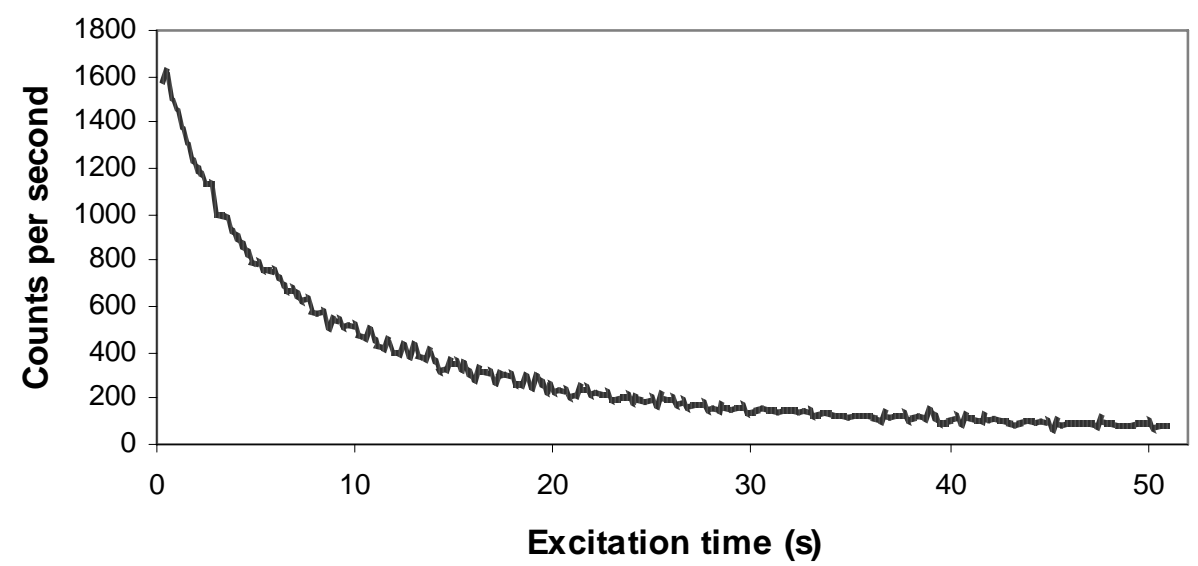

Fig. 4. Typical OSL curve (or response) for the Transfer Standard

For each irradiation, the response of the detector was defined as the sum of the light output from the TS for the first 5.355 seconds of room temperature readout (i.e., stimulation) at $80 \%$ blue LED power. Using only the initial OSL signal from the readout ensured that the signal to background ratio was high, and that 
therefore background (and especially variations in background) could be considered negligible $(<1 \%)$ relative to the dose signal. Table 1 shows the detector response at each dose delivered, while Figure 2.5 is a plot of the calibration curve along with the best fit line. The best fit equation for the calibration curve was determined to be:

$$
\text { TS Response }=48.22 \times \text { Dose }-31.94 \quad \text { Equation } 1
$$

where dose is in units of mRad. The linear regression was performed by EXCEL ${ }^{\circledR}$. The $\mathrm{R}^{2}$ value of this fit was 0.9995 .

Table 1. The transfer standard's (TS)

dose response to known beta irradiations $( \pm 5 \%)^{a}$

\begin{tabular}{cc}
\hline $\begin{array}{c}\mathrm{H}_{\mathrm{p}}(0.07) \\
(\mathrm{mrad})\end{array}$ & TS Response \\
\hline 300 & 14258 \\
400 & 19630 \\
600 & 29003 \\
700 & 38478 \\
800 & 33304 \\
1000 & 48385 \\
\hline
\end{tabular}

${ }^{\mathrm{a}} \mathrm{TS}$ response is defined as the light recorded by the OSL reader during the first 5.355 seconds of blue LED stimulation at $80 \%$ power.

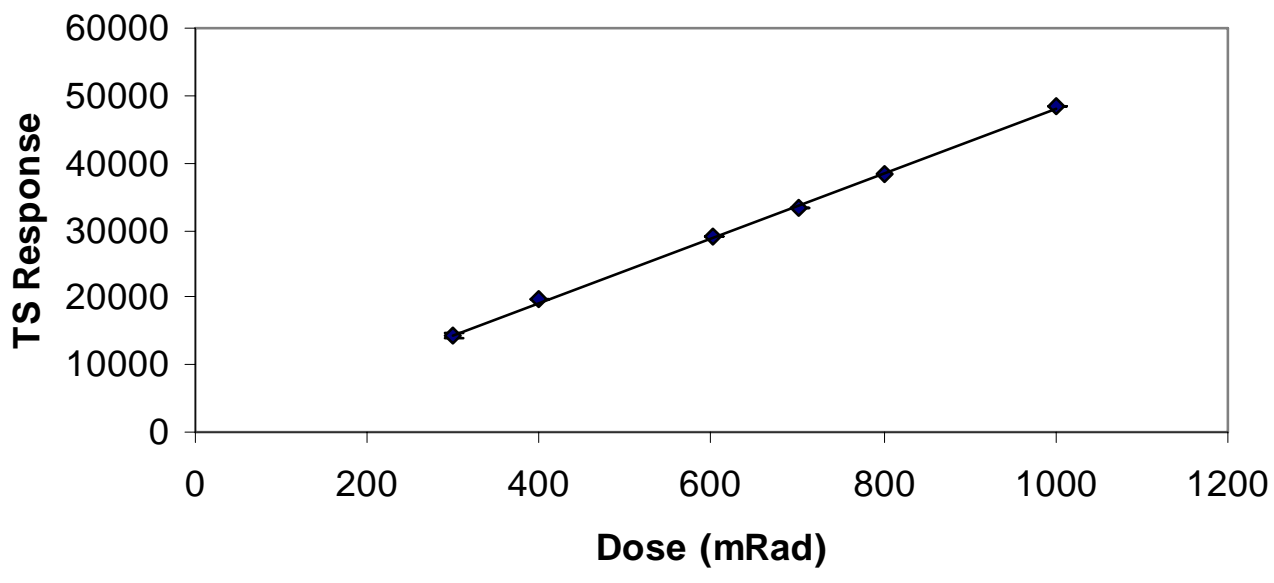

Fig. $5 .{ }^{90} \mathrm{Sr} /{ }^{90} \mathrm{Y}$ Dose response curve for the Transfer Standard. The line shown is a linear best-fit with the equation TS response $=48.22 \times$ Dose -31.94 calculated by EXCEL software. The $\mathrm{R}^{2}$ value for this fit was 0.9995 . TS Response or the dose response of the transfer standard is defined as the sum of the signal (or counts) recorded at room temperature during the first 5.355 seconds of blue LED stimulation at $80 \%$ blue LED power). 
After generating the calibration curve, the detector was placed in the $801 \mathrm{E}$ Irradiator for a 3 second beta irradiation. The resulting TL response was plugged into Equation 1 to calculate total dose, and then divided by the irradiation time to determine dose rate.

The dose rate of the $801 \mathrm{E}$ Irradiator beta source was determined to be $0.147+/-0.007 \mathrm{~Gy} / \mathrm{s}$.

\section{801E IRRADIATOR TIMING ACCURACY}

In order to determine the timing accuracy of the shutter mechanism in the 801E Irradiator, the TS was placed inside the irradiator after undergoing bleaching with blue light to remove residual OSL signal. Beta irradiations of $0.2,0.4,0.5,0.6,1,2$, and 3 seconds in length were programmed into the irradiator and carried out, with the detector response measured after each irradiation. Detector response was defined as previously stated in this report. Before each irradiation the OSL signal on the detector was bleached to remove residual signal. For each irradiation detector response was then converted to dose rate using Equation 1. Results are given in Table 2. Figure 3.6 shows the apparent dose rate as a function of irradiation time and indicates that irradiations of less than 0.5 seconds result in a substantial error in dose rate of up to $60 \%$. Therefore, irradiations of less than 0.5 seconds duration should not be performed with the model $801 \mathrm{E}$ irradiator.

Table 2. Transfer standard's response to $801 \mathrm{E}$ beta irradiations

\begin{tabular}{ccc}
\hline $\begin{array}{c}\text { Irradiation } \\
\text { Time } \\
(\mathrm{s})\end{array}$ & TS Response $^{\mathrm{a}}$ & $\begin{array}{c}\text { Apparent Equivalent } \\
\text { Dose Rate, } \mathrm{H}_{\mathrm{p}}(0.07) \\
(\mathrm{rad} / \mathrm{s})\end{array}$ \\
\hline 0.2 & 356670 & 36.98 \\
0.4 & 368359 & 19.10 \\
0.5 & 370549 & 15.37 \\
0.6 & 377179 & 13.04 \\
1.0 & 648803 & 13.45 \\
2.0 & 1411940 & 14.64 \\
3.0 & 2136926 & 14.77 \\
\hline
\end{tabular}

${ }^{\mathrm{a}}$ TS response is defined as the light recorded by the OSL reader during the first 5.355 seconds of blue LED stimulation at $80 \%$ power. 


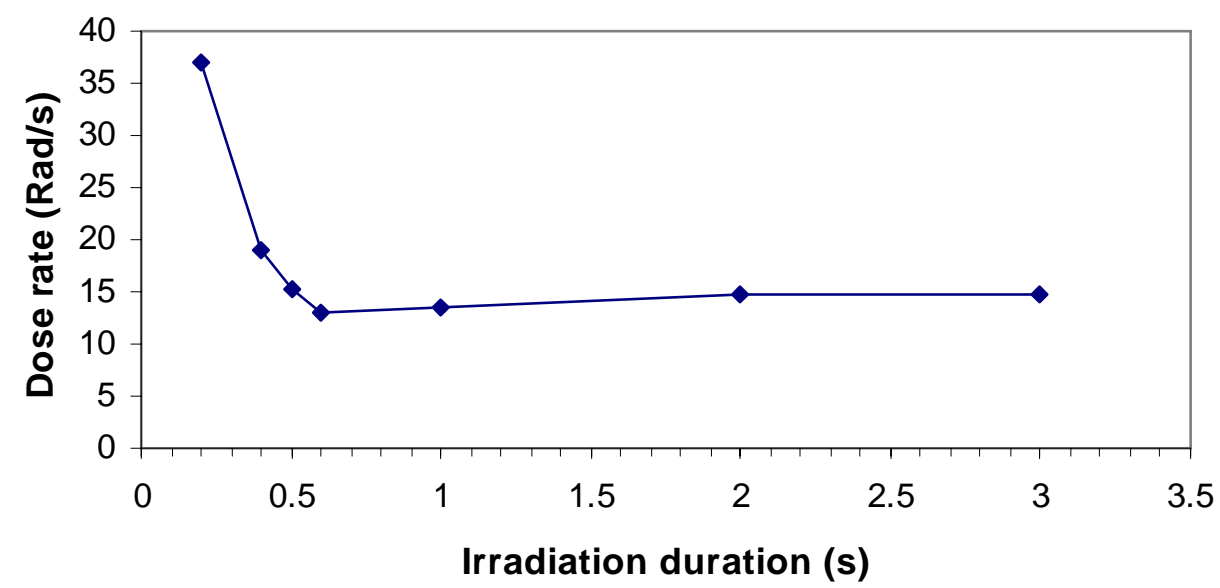

Fig. 6. Apparent dose rate of the 801E Irradiator as a function of irradiation duration.

\section{SOURCES OF UNCERTAINTY}

There are some sources of uncertainty associated with the dose rate determination of the $801 \mathrm{E}$ beta Irradiator. The dose value given by the controlling computer of the calibrated DOSAR Calibration Laboratory beta source has an associated uncertainty of less than $5 \%$ (at the $95 \%$ confidence level). This uncertainty is associated with factors such as variation in placement of the transfer standard on the phantom, source-to-target distance, and measurement uncertainties in the initial source calibration. The variance from irradiation to irradiation (with the TS placed on the same spot on the phantom each time) was measured by performing 3 identical 300-mRad DOSAR Calibration Laboratory exposures of the transfer standard. The resulting variance was found to be $3 \%$. Error propagation calculations resulted in an error in $801 \mathrm{E}$ Irradiator dose rate of $0.007 \mathrm{~Gy} / \mathrm{s}$. This error estimate does not include the following biases:

(1) There is a bias present in this work due to the fact that the DOSAR Calibration Laboratory beta source was calibrated in units of $\mathrm{H}_{\mathrm{p}}(0.07)$. Dose values quoted in this work are therefore shallow dose to tissue, and not dose to $\mathrm{Al}_{2} \mathrm{O}_{3}: \mathrm{C}$ or quartz.

(2) An additional bias is due to the fact that a steel plate was placed behind the TS during irradiations using the DOSAR Calibration Laboratory source. Because initial calibration of the DOSAR Calibration Laboratory source was done without the presence of steel, and because of the high energy of the ${ }^{90} \mathrm{Sr} /{ }^{90} \mathrm{Y}$ betas, there was most likely an increase in dose to the TS due to backscatter of beta particles from the steel plate, which would not have occurred had the steel not been there. This presumed increase in dose was not reflected in the dose value given by the controlling computer, which gave an underestimate of the actual dose received assuming no steel plate to be present. Irradiations with and without the steel plate would have to be done to determine the extent of the bias. 


\section{REFERENCES}

Akselrod, M.S., Kortov V.S., Gorelova E.A. 1993. "Preparation and properties of $\alpha-\mathrm{Al}_{2} \mathrm{O}_{3}: \mathrm{C}$ ". Radiat. Prot. Dosim. 47, 159-164.

Akselrod, M.S., Kortov V.S., Kravetsky D.J., Gotlib V.I. 1990. "Highly sensitive thermoluminescent anion-defect $\alpha-\mathrm{Al}_{2} \mathrm{O}_{3}: \mathrm{C}$ single crystal detectors." Radiat. Prot. Dosim. 33, 119-122.

Bøtter-Jenson L., Agersnap Larsen L.N., Markey B.G., McKeever S.W.S. 1997. " $\mathrm{Al}_{2} \mathrm{O}_{3}: \mathrm{C}$ as a sensitive OSL dosemeter for rapid assessment of environmental photon dose rates". Radiat. Meas. 27, 295-298.

Bøtter-Jensen L., S. W. SMcKeever, and A. G. Wintle 2003. Optically Stimulated Luminescence Dosimetry, Elsevier Press, New York.

McKeever, S. W. S, Markey B.G., Akselrod M.S. 1996. "Pulsed optically-stimulated luminescence dosimetry using $\alpha-\mathrm{Al}_{2} \mathrm{O}_{3}: \mathrm{C}$ ". Radiat. Prot. Dosim. 65, 267-272. 
APPENDIX A

DOSAR Calibration Laboratory ${ }^{90} \mathrm{Sr} /{ }^{90} \mathrm{Y}$ Source Calibration Report 
This calibration was performed as a part of the Measurement-Assurance Program carried out for the University of Michigan School of Public Health.

DG $8151 / 83$

DB $850 / 91$

1983 Sep 27

Page 1 of 2

\author{
U.S. DEPARTMENT OF COMMERCE \\ NATIONAL BUREAU OF STANDARDS \\ WASHINGTON, DC 20234
}

REPORT OF CALIBRATION

\author{
${ }^{90} \mathrm{Sr}$ Beta-particle Source \\ Submitted by University of Michigan \\ Ann Arbor, MI 48109
}

Received at NBS on 1983 Aug 12

Calibration date 1983 Aug 20

Beta-particle sources are calibrated in terms of the absorbed-dose rate to water. Absorbed-dose rate is determined from current measurements with an extrapolation ionization chamber that has a tissue-equivalent-plastic collecting electrode. The water absorbed-dose rate is given by

$$
\dot{D}=\frac{33.7 \times 1.111 \times S \times U}{1.197 \times A}\left(\frac{\Delta I}{\Delta d}\right)_{0} \mathrm{~Gy} / \mathrm{s}
$$

where $(\Delta I / \Delta d)_{0}$ is the rate of change of current (normalized to a reference temperature and pressure) with extrapolation chamber air-gap thickness as the thickness approaches zero, 33.7 is the mean energy expended per unit charge in air, 1.111 is the ratio of the mean stopping power of water to that of air, 1.197 is the density of air at the reference temperature and pressure $\left(22^{\circ} \mathrm{C}\right.$ and 1 standard atmosphere), $S$ is a correction for scatter from the chamber supports and the shield, $U$ is a correction for attenuation by the high-voltage electrode, and $A$ is an area. S is a function of the distance between source and chamber, and both $S$ and $U$ are functions of the beta-particle energies. For calibrations at a distance from the source surface, or when the source has a larger area than that of the collecting electrode, $A$ is the area of the collecting electrode. For calibrations at the surface of the source where the area is smaller than that of the collecting electrode, $A$ is the active area of the source, defined as the area within the $50 \%$ isodose line at the source surface. The listed diameter is $2 \sqrt{A / I}$. 
The source submitted was mounted at the center of the 1 -meter diameter aluminum plate (or "D") provided, and the extrapolation chamber was positioned at each of the six specified film badge locations around a semicircle with a $35-\mathrm{cm}$ radius. The rate of change of current with air-gap thickness was measured at each position with a $30-\mathrm{mm}$ diameter acrylic collecting electrode. No albedo correction was used when converting to absorbed dose in water.

The water absorbed-dose rate at a depth of $7 \mathrm{mg} / \mathrm{cm}^{2}$ is given in the table at each of the film badge locations in SI units (milligrays per second) and in special units (millirads per second). Location 6 is the farthest clockwise around the "D", as seen from above.

Information on the technical aspects of this report can be obtained from J. S. Pruitt, Radiation Physics C210, National Bureau of Standards, Washington, DC 20234, 301-921-2361.

Calibration performed by J. S. Pruitt $\int S P$ Report approved by R. Loevinger $\mathrm{R}$

For the Director

by

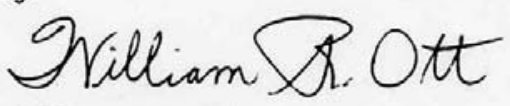

William R. Ott

Chief, Radiation Physics Division

Center for Radiation Research

National Measurement Laboratory

\begin{tabular}{|c|c|c|c|c|c|c|c|c|}
\hline Location & $\begin{array}{l}\text { Distance } \\
(\mathrm{mm})\end{array}$ & $\begin{array}{c}\text { Active } \\
\text { Area } \\
\text { A } \\
\left(\mathrm{mm}^{2}\right) \\
\end{array}$ & $\begin{array}{l}\text { Di ameter } \\
(\mathrm{mm})\end{array}$ & $\begin{array}{c}\text { Correction } \\
\text { S }\end{array}$ & $\underset{U}{\text { factors }}$ & $\begin{array}{l}\text { Wat } \\
\text { Absorbed } \\
\mathrm{mGy} / \mathrm{s}\end{array}$ & $\begin{array}{c}\text { lose } r \text { ate } \\
\mathrm{mr} \text { ad/s }\end{array}$ & \\
\hline $\begin{array}{l}1 \\
2 \\
3 \\
4 \\
5 \\
6\end{array}$ & 350 & 708 & 30 & 1.00 & 0.984 & $\begin{array}{l}0.0217 \\
0.0260 \\
0.0264 \\
0.0265 \\
0.0258 \\
0.0215\end{array}$ & $\begin{array}{l}2.17 \longleftarrow \\
2.60 \\
2.64 \\
2.65 \\
2.58 \\
2.15 \leftarrow\end{array}$ & $>$ Outli \\
\hline
\end{tabular}


ORNL/TM-2004/193

\section{INTERNAL DISTRIBUTION}

1-4. J. S. Bogard

5. J. M. Doktycz

\author{
6. Central Research Library \\ 7. ORNL Laboratory Records-RC \\ 8-9. ORNL Laboratory Records-OSTI
}

\section{EXTERNAL DISTRIBUTION}

10-12. S. M. Bernal, 3090 Deer Creek Court, Ann Arbor MI 48105

13. A. Kramer, Department of Anthropology, University of Tennessee, Knoxville TN 37996-0720

14. D. C. Weinand, Department of Anthropology, University of Tennessee, Knoxville TN 379960720 